\title{
Incidence of rectosigmoid adenomatous polyps in subjects without prior colorectal adenoma or cancer: a prospective cohort study
}

\author{
B Paillot, P Czernichow, P Michel, V Merle, A-M Queuniet, C Duval, H Daubert
}

\begin{abstract}
Background-Subjects without known colorectal adenomas or cancer constitute a large majority of the population where $85 \%$ of all cases of colorectal cancer are thought to occur. Consequently these people should be considered for screening to decrease mortality from colorectal cancer in the general population.

Aims-To estimate the incidence rate of rectosigmoid adenomas in these subjects. Methods-Subjects without adenomas or cancer at a previous examination which had visualised the rectosigmoid underwent a fibre endoscopy every three years. Endoscopic data and population characteristics were collected prospectively.

Results-A total of 450 subjects fulfilled the selection criteria; 287 (64\%) underwent at least two examinations, and 163 had three or more. At the second examination, with a mean delay of 39 months, the incidence rate of rectosigmoïd adenomas was $1.50 \%$ per patient year. The rate was $1.75 \%$ per patient year $(95 \%$ CI $0.80-3.33$ ) at the third endoscopy with an additional mean delay of 38 months. The cumulative incidence rate at six years was 7.3\% (95\% CI 4.3-10.3), representing a mean of $1.2 \%$ per patient year. This rate increased with age and was higher for men than for women after age adjustment ( $p<$ 0.03).

Conclusions-The incidence rates are very low compared with those of patients with prior adenomas. These results should be considered in establishing rectosigmoid adenoma screening strategies.

(Gut 1999;44:372-376)
\end{abstract}

Keywords: adenomatous polyps; epidemiology; incidence; colonic polyps; rectal neoplasms; sigmoid neoplasms

France

P Czernichow

Departement d'Epidémiologie et de Santé Publique, Centre Hospitalier et Universitaire, Rouen, France

V Merle

H Daubert

Correspondence to: Dr B Paillot, Centre des Tumeurs Digestives, Centre Hospitalier et Universitaire, 76031 Rouen Cedex, France.

Accepted for publication 21 October 1998 mated at $10-15$ years. ${ }^{9}$ Colonoscopy with polypectomy is associated with a reduced mortality from colorectal cancer. ${ }^{10}{ }^{11}$ The prevalence of colorectal adenomas and some risk factors are known. ${ }^{12}$ The rate of adenoma recurrence has already been estimated ${ }^{12}$ and an effective interval between endoscopic examinations has been evaluated in a large group of patients with previous colorectal adenomas. ${ }^{13}$ Although guidelines for the prevention of colorectal cancer have been published, ${ }^{14} 15$ there are few data concerning the incidence of colorectal adenomas in populations without previously diagnosed adenomas, ${ }^{16-19}$ although this group represents the majority of the population. Indeed, approximately $85 \%$ of all cases of colorectal cancer are thought to arise in people without (or without previously) diagnosed adenomas. That is the reason why this low risk, but large group should obviously not be excluded from screening, if a decrease in mortality from colorectal cancer is to be expected in the general population. An estimate of the incidence rate of colorectal adenomatous polyps in this population is thus necessary to help define an effective prevention strategy. The aim of this study was to estimate the incidence rate of rectosigmoid adenomas in subjects without prior rectosigmoid adenomas or cancer.

\section{Methods}

PATIENTS

Since July 1979 our Cancer Centre has carried out a prevention and screening programme for colorectal cancer based on endoscopy. This programme was proposed to 1745 subjects who had a previous colonic endoscopy in our hospital and whose life expectancy was not hypothetically shortened, particularly by an evolutive cancer, or cardiac, renal, hepatic, or pulmonary failure. The first endoscopy could have already been done for screening or for any other reason. Therefore, 677 subjects (mean (SD) age 55.2 (11.1) years, $60.3 \%$ women) had at least two rectocolic fibre endoscopies between July 1979 and July 1992. There could be several reasons for performing the initial examination: macroscopic $(29.1 \%)$ or occult $(6.2 \%)$ rectal bleeding, intestinal symptoms $(28.1 \%)$, a personal history of rectocolic polyp $(7.4 \%)$ or cancer $(7.1 \%)$, breast cancer $(8.6 \%)$, uterine cancer $(9.9 \%)$, miscellaneous cancer $(5.3 \%)$, or a first degree family history of colorectal polyp $(3.2 \%)$ or cancer $(14.2 \%)$; the most frequent reason was screening $(72.1 \%)$, and the main aim of the endoscopist was to look for neoplastic lesions. In this group, subjects without previous colorectal polyp or cancer and whose initial endoscopy did not show any adenoma or cancer entered this prospective cohort study. 
SREENING PROGRAMME DESIGN

Based on an estimated average of 10-15 years of growth from an adenoma to a cancer, our programme proposed a total colonoscopy every six years. As rectosigmoid is the main site of the adenomas, an additional flexible sigmoidoscopy was proposed in the interval of two colonoscopies, in an attempt to improve efficacy. Thus, a flexible sigmoidoscopy or a complete colonoscopy was alternatively proposed every three years. Three years after the previous endoscopy, each subject was contacted by mail a few weeks before each examination which was performed following written consent. Although the interval between two examinations was intended to be three years, it may have been shorter or longer at the request of the subject, or due to delay.

ENDOSCOPIC PROCEDURES

Fibre sigmoidoscopies were performed without anaesthesia after one Normacol enema. Complete colonoscopies were performed with sedation and after intestinal cleaning by a polyethyleneglycol solution. If a neoplastic lesion was discovered on sigmoidoscopy, a total colonoscopy to examine the rest of the colon was performed. Only sigmoidoscopies which visualised more than $35 \mathrm{~cm}$ from the anal margin (as measured when pulling back the colonoscope) were selected. When a total colonoscopy was performed, only the data concerning the rectosigmoid were taken into account for this study.

\section{STATISTICAL METHODS}

For each subject included in the programme each successive examination was registered and analysed. The first positive examination (diagnosis of a neoplastic lesion) or the last negative examination defined the end point of follow up for statistical analysis. Data for age, sex, indications of the first examination, and past personal and first degree relatives' history of cancer and/or colorectal polyps were prospectively collected from each subject using a standardised questionnaire. The cumulative incidence rate and $95 \%$ confidence intervals $(95 \% \mathrm{CI})$ of rectosigmoid adenomas was estimated for men and women, and for each age group at each successive examination (whatever the real date), and at six years of follow up (whatever the real number of examinations performed at that time). The size of each polyp (or the largest when several polyps were diagnosed) was recorded. The influence of age, sex, history of first degree relatives' colorectal cancer or adenomas, and intestinal symptoms, on the occurrence of colorectal adenomas was tested using the log rank test. Finally, the influence of sex on the occurrence of adenomas, with adjustment for the confounding effect of age, was tested using the log rank test. All statistical tests were performed using BMDP software. ${ }^{20}$

\section{Results}

Between July 1979 and July 1992, 450 subjects fulfilled the inclusion critera and underwent 1638 endoscopies. Table 1 presents the popu-
Table 1 Characteristics of 450 subjects free of previous adenomas or cancer at the first examination

\begin{tabular}{lc}
\hline & $n(\%)$ \\
\hline Sex & $152(33.8)$ \\
Male & $298(66.2)$ \\
Female & \\
Age (years) & $170(37.7)$ \\
$<50$ & $163(36.2)$ \\
$50-59$ & $89(19.7)$ \\
$60-69$ & $28(6.2)$ \\
$\geqslant 70$ & $40(8.8)$ \\
Personal history & $54(12.0)$ \\
Breast cancer & $22(4.8)$ \\
Uterine cancer & $13(2.8)$ \\
Other cancers & $61(13.5)$ \\
First degree relative history & $142(31.5)$ \\
Colorectal cancer & $131(29.1)$ \\
Colorectal polyp & $345(76.6)$ \\
Reasons for doing first examination & \\
Intestinal symptoms & \\
Rectal bleeding & \\
Screening &
\end{tabular}

^Several reasons per subject are possible.

lation characteristics. No differences were observed when comparison was made with the 677 subjects who joined the screening programme, except for age, this subgroup being two years younger. The mean duration of follow up was 54 months (range 6-161) with 154 subjects (34\%) followed up for more than six years. In 188 cases $(41.8 \%)$ the initial examination was a fibre sigmoidoscopy; for 262 subjects a colonoscopy was performed which was complete in only 111 cases $(24.7 \%)$. During the study 287 subjects ( $64 \%$ ) had only two examinations, 116 subjects $(26 \%)$ had three, and $47(10 \%)$ had four or more; 32 patients were diagnosed with one or several concomitant rectosigmoid adenomas. No rectosigmoid cancer was diagnosed during the study. None of the adenomas removed was dysplastic.

INCIDENCE RATE AT EACH SUCCESSIVE

EXAMINATION

A total of 287 subjects (64\%) underwent only two examinations with a mean delay of 39 months (but up to the seventh year) and one or more adenomas were found in 22 of them. The incidence rate at this second examination was 1.5 per 100 patient years (95\% CI 0.94-2.27). The size of the adenomas (or the largest when there was more than one) was under $5 \mathrm{~mm}$ for six patients, between 5 and $9 \mathrm{~mm}$ for 11 patients, between 10 and $14 \mathrm{~mm}$ for two patients, and $15 \mathrm{~mm}$ or larger for three patients. A total of 116 subjects (26\%) whose second endoscopy was negative underwent a third examination, after an additional mean delay of 38 months. In nine patients, one or more adenomas were found with an incidence rate of 1.75 per 100 patient years (95\% CI $0.80-3.33$ ). The size of the adenomas (or the largest when there was more than one) was under $5 \mathrm{~mm}$ for three patients, between 5 and $9 \mathrm{~mm}$ for two patients, between 10 and $14 \mathrm{~mm}$ for three patients, and $15 \mathrm{~mm}$ or larger for one patient.

CUMULATIVE INCIDENCE RATE OF RECTOSIGMOID ADENOMAS AT SIX YEARS

Table 2 shows the cumulative incidence rate of rectosigmoid adenomas at six years. With 22 cases of rectosigmoid adenomas diagnosed 
Table 2 Cumulative incidence rate at six years of rectosigmoid adenomas in 450 subjects free of previous adenomas or cancer

\begin{tabular}{|c|c|c|c|c|c|}
\hline & $n$ & $\begin{array}{l}\text { Patients with } \\
\text { adenomas }(n)\end{array}$ & $\begin{array}{l}\text { Cumulative } \\
\text { rate }(\%)\end{array}$ & $95 \% C I$ & $p$ Value \\
\hline All subjects & 450 & 22 & 7.3 & $4.3-10.3$ & \\
\hline \multicolumn{6}{|l|}{ Sex } \\
\hline Male & 152 & 13 & 12.9 & $6.1-19.7$ & \\
\hline Female & 298 & 9 & 4.5 & $1.5-7.5$ & 0.03 \\
\hline \multicolumn{6}{|c|}{ Age at first endoscopy (years) } \\
\hline$<50$ & 170 & 5 & 4.2 & $0.5-7.9$ & \\
\hline $50-59$ & 163 & 9 & 8.1 & $2.9-13.4$ & \\
\hline$\geqslant 60$ & 117 & 8 & 10.9 & $3.4-18.4$ & $0.02^{\star}$ \\
\hline
\end{tabular}

${ }^{\star}$ Overall test: a significant difference was only observed between $<50$ and $\geqslant 60$ years. $\mathrm{CI}$, confidence interval. approach to that of the present study. ${ }^{17}$ Their aim was to evaluate the results of flexible sigmoidoscopy three years after a negative examination in an average risk person (asymptomatic, and without first degree relatives with colorectal polyps or cancer, inflammatory bowel disease, a personal history of colorectal polyps or cancer, breast or uterine cancer, or Peutz-Jeghers syndrome). With a mean interval of 41 months between examinations, among 259 persons who were rescreened, $15(6 \%)$ had one or more adenomas, and none had cancer. This study and the present one were both performed in average or low risk groups from Western countries. These results support the hypothesis that the annual incidence rate of rectosigmoid adenomas for subjects 50 years and older is approximately $1-2 \%$.

Another recent study from the same group, evaluating the five year incidence of adenomas in the same asymptomatic average risk persons, and based on total colonoscopy, reported quite similar results. ${ }^{19}$ Of 154 persons who underwent a second screening, a mean of 66 months after the initial negative colonoscopy, $41(27 \%)$ were found to have at least one adenoma, $61 \%$ of which were located proximal to the splenic flexure. These rates are more than twice lower than the $32.0 \%$ reported by the US national polyp study group ${ }^{13}$ in patients rescreened three years after an initial polypectomy. It is also important to note that in the study by Rex et al and in our investigation no cancer was detected, even after five years.

It is well known that some polyps, especially small ones, may be missed at a first examination and obviously this fact cannot be excluded in our cohort. These polyps, only diagnosed at a further examination, may falsely increase the apparent incidence of new polyps. Some of our subjects had symptoms at their first examination and that too may be associated with an increased risk of neoplastic lesions. However, small polyps which could be missed are usually asymptomatic. It is also noteworthy that the second and following examinations were never diagnostic but screening ones. All these facts reinforce the significance of the low incidence rate in our cohort.

Two other important findings in the present study are the increased incidence rate with age and in men. An increased prevalence of adenomatous polyps with age has been well established, ${ }^{12122}$ and has recently been confirmed $^{23-25}$ and reviewed. ${ }^{26}$ The influence of age on incidence has also been identified by Neugut et al for their entire population (with or without abnormalities on index colonoscopy) ${ }^{17}$ and by Winawer et al in patients with previous colorectal adenomas. ${ }^{13}$

Sex is also an important characteristic when considering the risk of colorectal neoplasias. Although it remains controversal, ${ }^{12}$ the higher prevalence of adenomas in men has been extensively documented in necropsy series, ${ }^{22}$ in clinical data, ${ }^{21}$ and especially with multivariate analysis $^{23} 25$ in asymptomatic patients with a family history of colorectal cancer ${ }^{27}{ }^{28}$ as well as in patients with prior colorectal adenomas. ${ }^{13}$ The present study of the incidence rate is the adenoma, which was expressed as "a cumul tive incidence of approximately $16 \%$ after three years", also suggesting a rather high incidence rate. ${ }^{18}$ It is important to note that these two series were small. Rex et al had a very similar 
only one to document a significantly higher risk in men than in women. In fact, all the workers studied by Lewis et $a l,{ }^{16}$ and $90 \%$ of the population studied by Rex and colleagues ${ }^{17}$ were men, which obviously makes a comparison impossible. These results have only been previously reported in subjects without prior colorectal neoplasias by Neugut et al, but due to the size of their sample, those results were not statistically significant. ${ }^{18}$

Based on the inclusion criteria, the patients in this study did not have prior colorectal adenomas or cancer, but some did have a prior history of other cancers, or a family history of colorectal cancer. A personal history of cancer was noted in $25.8 \%$ of the subjects, including $8.8 \%$ with previous breast cancer and $12 \%$ with uterine cancer. Furthermore $16.3 \%$ had a first degree relative with a history of colorectal cancer or polyps (table 1). These conditions could be associated with a risk of colorectal neoplastic lesions different to that in the general population. Many studies have shown that a history of adematous polyps or colorectal cancer in a family member is associated with a high risk of adenomatous polyps of the rectum or colon. ${ }^{28}{ }^{29}$ These data suggest that the population studied here could have been at a slightly higher risk for colorectal adenomas than the general population. This would enhance the low rate that we have observed. On the other hand, it should be kept in mind that two recent reports revealed no increased prevalence in adenomas in women with breast cancer screened with colonoscopy ${ }^{3031}$ and, to our knowledge, there is no proved association between endometrial cancer and adenomatous colorectal polyps.

Our cohort was not intended to be representative of the general French population and may differ particularly for age and personal or family history. The mean age of our subjects was 53 years at their first examination. This is quite close to the mean age of 56.4 in the study by Rex et al, and may explain the similar results. ${ }^{17}$ In our series, $66 \%$ of the subjects were women while in the general French population over 50 years old $58 \%$ were women. ${ }^{32}$ The possible differences between the characteristics of the population in this study and the general population in Western countries will probably not affect our main results which are highly significant. Thus, only small differences in the evaluation of the incidence rates are expected. Once again, the similarities with the Indianapolis study ${ }^{18}$ are important and the characteristics of our patients are probably those of potentially compliant individuals in a preventive programme in a Western country.

While cancer seems to occur most frequently in the rectum and distal colon, ${ }^{33}$ the segmental distribution of adenomas within the large bowel is controversial and may be influenced by age and methodology. However, there is a certain consensus that large adenomas and/or adenomas with dysplasia are found more often in the rectum and the sigmoid colon, ${ }^{12} 2{ }^{22}$ thus justifying focusing on the rectosigmoid in the present work and the study by Rex et al. This is also a strong argument for screening programmes based on sigmoidoscopy.

These results could help to develop more effective rectosigmoid adenoma screening strategies. The findings, as well as the duration of the polyp-cancer sequence, contribute to support the proposals of a sigmoidoscopy every six to 10 years ${ }^{10}$ or even "once only", ${ }^{34}$ not only in the high risk population or in patients with positive faecal occult blood tests, but also in the average or low risk population over 50 years of age, in order to decrease the overall mortality from colorectal cancer.

This work was supported in part by a grant of the Ligue Nationale Française Contre le Cancer (Comités départementaux de l'Eure et de la Seine-Maritime). The authors thank $\mathrm{Mr}$ $\mathrm{R}$ Medeiros for his advice in editing the manuscript.

1 American Cancer Society. Cancer facts and figures-1990. Atlanta: American Cancer Society, 1990.

2 Ménégoz F, Black RJ, Arveux P, et al. Cancer incidence and Menégoz F, Black RJ, Arveux P, et al. Cancer incidence and
mortality in France in 1975-95. Eur f Cancer Prev 1997;6: mortality

3 Muto T, Bussey HJ, Morson BC. The evolution of cancer of the colon and rectum. Cancer 1975;36:2251-70.

4 Madara JL, Harte P, Deasy J, et al. Evidence for an adenoma-carcinoma sequence in dimethylhydrazineinduced neoplasms of rat intestinal epithelium. Am $\mathcal{F}$ Pathol 1983;110:230-5.

5 Fearon ER, Vogelstein B. A genetic model for colorectal tumorigenesis. Cell 1990;61:759-67.

6 Simons BD, Morrison AS, Lev R, et al. Relationship of polyps to cancer of the large intestine. $\mathcal{F}$ Natl Cancer Inst 1992; 84:962-6.

7 Stryker SJ, Wolf BG, Culp CE, et al. Natural history of untreated colonic polyps. Gastroenterology 1987;93:100913.

8 Atkin WS, Morson BC, Cuzick J. Long-term risk of colorectal cancer after excision of rectosigmoid adenomas. $N$ Engl tal cancer after excision of

9 Morson BC, Dawson IMP. Gastro-intestinal pathology. 2nd Morson BC, Dawson IMP. Gastro-intestinal pathology. 2nd
edn. London: Blackwell Scientific Publications, 1979:637. 10 Selby JV, Friedman GD, Quesenberry CP Jr, et al. A case control study of screening sigmoidoscopy and mortality from colorectal cancer. $N$ Engl F Med 1992;326:653-7.

11 Müller AD, Sonnenberg A. Prevention of colorectal cancer by flexible endoscopy and polypectomy. A case-control study of 32702 veterans. Ann Intern Med 1995;123:904-10.

12 Peipins LA, Sandler RS. Epidemiology of colorectal adenomas. Epidemiol Rev 1994;16:273-97.

13 Winawer SJ, Zauber AG, O'Brian MJ, et al. Randomized comparison of surveillance intervals after colonoscopic removal of newly diagnosed adenomatous polyps. $N$ Engl $\mathcal{F}$ Med 1993;328:901-6.

14 Conférence de consensus. Préventon, dépistage et prise en charge des cancers du colon. Gastroenterol Clin Biol charge des cancers

15 Winawer SJ, Fletcher RH, Miller L, et al. Colorectal cancer screening: clinical guidelines and rationale. Gastroenterology 1997;112:594-642.

16 Lewis RJ, Lerman SE, Schnatter AR, et al. Colorectal polyp incidence among polypropylene manufacturing workers. $\mathcal{F}$ Occup Med 1994;36:174-81.

17 Rex DK, Lehman GA, Ulbright TM, et al. The yield of a second screening flexible sigmoidoscopy in average-risk persons after one negative examination. Gastroenterology 1994;106:593-5.

18 Neugut AI, Jacobson JS, Ahsan H, et al. Incidence and recurrence rates of colorectal adenomas: a prospective study. Gastroenterology 1995;108:402-8.

19 Rex DK, Cummings OW, Helper DJ, et al. 5-Year incidence of adenomas after negative colonoscopy in asymptomatic of adenomas after negative colonoscopy in asymptomatic

20 Dixon WJ (ed). BMDP statistical software manual. Berkeley: University of California Press, 1992.

21 Faivre J, Boutron MC, Bataillon P. Epidemiology of adenoma: clinical data. In: Faivre J, Hill MJ, eds. Causation and prevention of colorectal cancer. Amsterdam: Elsevier Science, 1977:29-37.

22 Vatn MH. Epidemiology of adenomas: autopsy data. In: Faivre J, Hill MJ, eds. Causation and prevention of colorectal cancer. Amsterdam: Elsevier Science, 1977:13-27.

23 Rex DK, Lehman GA, Ulbright TM, et al. Colonic neoplasia in asymptomatic persons with negative fecal blood tests: influence of age, gender, and family history. Am 7 Gastroenterol 1993;88:825-31.

24 Cannon-Albright LA, Bishop DT, Samowitz W, et al. Colonic polyps in an unselected population: prevalence, characteristics, and associations. Am $\mathcal{f}$ Gaestroenterol 1994; 89:827-31.

25 Jass JR, Young PJ, Robinson EM. Predictors of presence, multiplicity, size and dysplasia of colorectal adenomas. A necropsy study in New Zeland. Gut 1992;33:1508-14. 
26 Rex DK. Colonoscopy: a review of its yield for cancers and adenomas by indication. Am $\mathcal{f}$ Gastroenterol 1995;90:35365.

27 Burt RW, Bishop DT, Cannon LA. Dominant inheritance of adenomatous colonic polyps and colorectal cancer. N Engl f Med 1985;312:1540-4

28 Gaglia P, Atkin WS, Whitelaw S, et al. Variables associated with the risk of colorectal adenomas in asymptomatic patients with a family history of colorectal cancer. Gut 1995;36:385-90.

29 Bonelli U, Martines H, Conio M. Family history of colorectal cancer as a risk factor for benign and malignant tumors of the large bowel: a case-control study. Int 7 Cancer 1988; 41:513-17.

30 Murray TI, Neugut AI, Garbowski GC, et al. Relationship between breast cancer and colorectal adenomatous polyps. A case-control study. Cancer 1992;69:2232-4.

31 Rex DK, Sledge GW, Harper PA, et al. Colonic adenomas in asymptomatic women with a history of breast cancer. $A m \mathcal{F}$ Gastroenterol 1993;88:2009-14.

32 Ministère Français des Affaires Sociales. Annuaire des statistiques sanitaires et sociales. Paris: La documentation tiques sanitaires et socia.

33 Cooper GS, Yuan Z, Landefeld CS, et al. A national population-based study of incidence of colorectal cancer and age. Cancer 1995;75:775-81

34 Atkin WS, Hart A, Edwards R, et al. Uptake, yield of neoplasia, and adverse effects of flexible sigmoidoscopy screening. Gut 1998;42:560-5. 